\title{
EL ACCESO A LA JUSTICIA CONTENCIOSO ADMINISTRATIVA COMO DERECHO FUNDAMENTAL EFECTIVO ${ }^{1}$

\author{
Access to the Contentious Administrative Justice as \\ Effective Fundamental Right ${ }^{1}$
}

\section{$\underline{\text { Abraham Zamir Bechara Llanos }}^{2}$}

Fecha de Recepción: Noviembre 4 de 2013

Fecha de Aceptación: Noviembre 11 de 2013

SUMARIO: 1. Introducción; 2. Desarrollo; 2.1 Importancia de la efectividad del Derecho en la Jurisdicción de lo Contencioso Administrativo; 2.1.1 Los Derechos Fundamentales y la Acción de Tutela; 2.2 La Justicia

Contenciosa Administrativa deben armonizarse con la Nueva Carta de 1991; 2.3 El funcionamiento y acceso a la Administración de Justicia, una realidad que nos interesa a todos; 2.4 El alcance del Derecho Fundamental de acceso a la Administración de Justicia, su sentido jurisprudencial; 2.5 ¿Está al alcance de todos los colombianos acceder a la Jurisdicción Contenciosa Administrativa?; 3.1 Criterios de solución a la problemática del acceso a la Jurisdicción Contenciosa Administrativa; 4. Conclusiones;

5. Referencias bibliográficas.

\footnotetext{
${ }^{1}$ El presente artículo es resultado de las reflexiones surgidas con ocasión a la realización del posgrado de Maestría en Derecho modalidad Investigación, de la División de Ciencias Jurídicas de la Universidad del Norte.

${ }^{2}$ Abogado y Especialista (Ex-Becario Unilibre) en Derecho Constitucional de la Universidad Libre sede Cartagena. Maestrando en Derecho Modalidad Investigación. Línea: Asuntos Públicos y Administración de Justicia. Universidad del Norte.
} 


\section{COMO SE CITA ESTE ARTÍCULO (APA 6)}

Bechara Llanos, A. Z. (2014) El acceso a la justicia contencioso administrativa como derecho fundamental efectivo. (Y. Carrillo De la rosa, Ed.) Revista Jurídica Mario Alario D'Filippo, VI (11), pág. 81-93

\section{RESUMEN}

Este artículo recoge el argumento central de la defensa de los derechos fundamentales como componente de nuestro Estado social de derecho, y del acceso a la justicia contenciosa administrativa como derecho fundamental efectivo y como garantía de amparo para todos los ciudadanos colombianos. Esta última se instituye como un valor superior de nuestros tiempos, en tanto que la relación y jerarquía de principios y normas constitucionales muestran la hoja de ruta para todas las instituciones y ramas que componen el derecho de nuestro ordenamiento jurídico. Su función es dinamizadora e integradora, al mirar más allá de lo que las herramientas dogmáticas presentan en cuestión de la aplicación de las leyes en los casos concretos; busca, además, mirar la misión de la justicia administrativa y la contenciosa, que se encargan de los litigios que nacen de los ciudadanos con el Estado y de las relaciones y negocios jurídicos que de ellos surjan, convirtiéndose así en parámetros de armonía a la hora de aplicar los criterios de interpretación normativa.

\section{PALABRAS CLAVE}

Acceso a la justicia, jurisdicción contenciosa administrativa, derecho fundamental efectivo, Estado social de derecho.

\section{ABSTRACT}

This article presents the central argument of the defense of fundamental rights as a component of our social state of law, and access to the administrative justice as a fundamental right and effective guarantee of protection for all Colombian citizens. The latter is established as a higher value of our time, while the relation and hierarchy of constitutional principles and norms show the roadmap for all institutions and branches that make up the right of our legal system. Its function is revitalizing and inclusive, to look beyond what dogmatic tools present within the enforcement in specific cases; seeks also to look at the mission of administrative justice and contentious, that handle disputes arising between citizens against the State and also the relations and legal transactions which they arise, thus becoming parameters harmony when to applying the criteria of normative interpretation.

\section{KEYWORDS}

Access to justice, administrative jurisdiction, effective fundamental right, state of law. 


\section{INTRODUCCIÓN}

Este artículo enfrenta la problemática del acceso a la justicia contencioso administrativa como derecho fundamental efectivo, partiendo de la base que los derechos fundamentales se instituyen para pleno reconocimiento tanto de las autoridades públicas como privadas, lo que nos ocupa aquí, es determinar que si el desconocimiento al acceso a la justicia contenciosa administrativa, constituye una violación al derecho fundamental que se configura en procura de acceder a la administración de justicia. La hipótesis o tesis que defendemos, es que si no existen los mecanismos que garanticen el acceso a la justicia contencioso administrativa, como derecho fundamental a la tutela judicial efectiva, no se le están dando cumplimiento al mandato constitucional que refleja el Artículo 229, al decir que se garantiza el derecho de toda persona para acceder a la administración de justicia.

El principal aspecto, que presenta dificultad en el acceso a la jurisdicción contencioso administrativa, es el factor económico, puntualmente en lo cuantioso de las demandas contra el Estado por reparación directa de los daños ocasionados en función de la administración, sobre un particular lesionado. Miremos un ejemplo que trae la doctrina:

No dar cumplimiento a una sentencia judicial debidamente ejecutoriada por que la entidad estatal condenada se encuentra en proceso de liquidación o en proceso de restructuración de pasivos. Si bien es cierto que las entidades en liquidación no pueden ser ejecutadas en razón de estar cobijadas por razón de un fuero especial contra procesos ejecutivos y por ende contra medidas cautelares de embargo y secuestro. En principio, se podría decir que ello es justificable como medida eficaz para que el proceso de liquidación llegue a feliz término, sin contratiempos y de esta manera resolver los problemas financieros de la entidad que se halle en esa situación. Pero la dificultad es que muchas entidades estatales que, encuentran en estado de liquidación, abusan de la misma de manera flagrante, ya que no dan cumplimiento al pago de sentencias a pesar de estar debidamente reconocido el crédito dentro de los pasivos de la entidad en liquidación.

(Pérez, 2010, p. 587)

El presente artículo desarrolla el siguiente problema de investigación: ¿La concreción del principio de justicia como efectividad del derecho establece un avance en el objeto de estudio de la jurisdicción de lo contencioso administrativo? La tesis que construiremos a lo largo del mismo, es que la Jurisdicción de lo Contencioso Administrativo, debe cumplir el postulado del principio de justicia estrechamente ligado a la necesidad de un derecho efectivo en esta jurisdicción. El propósito es que con este estudio se encuentren herramientas de reflexión en torno a la problemática aquí planteada, para así hallar escenarios de construcción teórica que permitan avanzar en el hallazgo de soluciones a las cuestiones esbozadas en este documento. La metodología abarca un enfoque descriptivo, y bibliográfico, con los cuales formaremos nuestro criterio en el avance y desarrollo este artículo de investigación. En lo descriptivo se estudiará si en la jurisdicción de lo contencioso administrativo, el principio de justicia cumple con los postulados del Estado social de derecho en torno a la efectividad de esta jurisdicción, en lo bibliográfico, nos apoyaremos en estudios ya realizados que permitan contrastar con nuestros argumentos, y así consolidar nuevos enfoque de la temática propuesta. La utilidad precisamos es la de encontrar 
puntos de consenso que permitan la reflexión y critica, sobre la efectividad del derecho en la jurisdicción contenciosa administrativa.

Hoy en día el derecho como sistema jurídico enfrenta múltiples problemas que van de la mano con la idea de una justicia que satisfaga las necesidades principales dentro de un ordenamiento legal. El abordaje de los distintos tópicos que ostenta el derecho en la posmodernidad se armoniza cada día más con la tesis de que el derecho es un medio de control social, esta afirmación presupone el entendido, que la razón primordial del derecho como medio garantizador del control social sea preservar el equilibrio de poderes dentro de un Estado de derecho o nación.

Ya la vieja división de poderes indicaba que las ramas del poder público estaban integradas por el legislativo, el ejecutivo y el judicial, propuesta visionada por el barón de Montesquieu hace ya varios lustros; su propuesta era visionaria en aquella época, hablamos de la Francia revolucionaria, ya que la única noción de poder que se tenía en ese entonces era el poder divino que encarnaba el rey emanado de Dios, este derecho secular se caracterizó por la sacralización de las leyes, y por la no aplicación del principio de legalidad en todas las actuaciones judiciales. Y así nació también el derecho administrativo como una necesidad de afrontar los problemas que surgían de las relaciones estatales con sus administrados. La revolución de 1789 constituye únicamente un paréntesis dentro de la continuidad de la jurisdicción administrativa francesa de inspiración monárquica. (Ospina, 2009, p. 26). Lo que indica el sentido del rey sobre la legislación vigente, la toma de decisiones era adoptada exclusivamente por el consejo del rey, presentando un vicio de parcialidad sobre las decisiones que se debían tomar en litigios donde podría estar condenado el Estado, es así como en un primer momento la efectividad del derecho en la jurisdicción de lo contencioso administrativo quedaba relegada a un derecho secular y monárquico como el que empero en la etapa de nacimiento de esta jurisdicción en Francia.

En este orden de ideas hablar de efectividad del derecho, es visionar al derecho a través del principio de justicia, al llevar el tópico central de esta investigación el cual es la efectividad del derecho frente a la jurisdicción de los contencioso administrativo, es mirar si en esta jurisdicción del derecho ordinario se está cumpliendo con los postulados del principio de la justicia del derecho. Como lo ilustra Carrillo (2009):

Progresivamente se ha ido admitiendo, que la sujeción a la ley no es ni la única, ni la más importante regla de la dogmática jurídica. La misma filosofía positivista del derecho decimonónica, en su versión antiformalista, criticó la regla de sujeción a la ley, por considerar que esta, al ser incompleta, llena de vacíos, incoherente, plagada de contradicciones, y en ocasiones ambiguas, no contenía todo el derecho. Hoy se admite, que al lado de este principio debe reconocerse el que una de las funciones sociales del derecho es producir decisiones justas y no únicamente garantizar la seguridad. Incluso autores positivistas como HART, sostienen que el derecho debe contener y garantizar un mínimo de justicia. (p.26).

La efectividad del derecho administrativo como reflejo de la evolución del Estado, debe traducirse, en una aproximación a los postulados centrales del nuevo Estado de derecho, con connotaciones sociales. En un primer lugar de este postulado, debe anotarse que las relaciones entre el Estado y 
los particulares han vendido cambiando a lo largo de la misma evolución histórica del concepto Estado-nación, como relación al cambio de poder y a la transformación del mismo, operando en el unos límites y controles racionales, a lo que anteriormente era una fuerza desmedía estatal, que conducía a formas de autoritarismos salvajes, en los cuales no operaban ni las más mínimas restricciones.

A razón de esto, nace la idea del equilibrio en el ejercicio del poder, traducida en pesos y contrapesos, que hicieran de la gestión pública un mejor ejercicio ahora controlado, dinamizador y encontrando restricciones a su uso desmedido. Se deja a un lado la arbitrariedad del no sometimiento a las decisiones judiciales, los actos y actividades realizadas en función pública, y sus posibles consecuencias, como detrimentos, lesiones, perjuicios. Etc. Que pudieren ocasionarse precisamente, en ese uso del poder sin limitaciones.

La efectividad que reclama el pueblo, debe traducirse en una justicia contenciosa administrativa, capaz de llegar a solucionar las controversias que se desarrollen en la actividad y relación ciudadano- Estado, o Estado- administrado. Esta efectividad del derecho administrativo, enmarcada en el Estado de derecho actual, reclama el cumplimiento de los derechos fundamentales, que los ciudadanos ya son titulares, por mandato constitucional, es que de esta manera por ejemplo, el derecho fundamental de acceso a la administración de justicia, en el caso de la jurisdicción contenciosa, no presenta criterios de efectividad. El tópico de las decisiones judiciales, debe ser valorado integralmente, en este caso como la jurisdicción a través de sus fallos, garantizan la protección de los derechos constitucionalmente protegidos a los administrados dentro del Estado de derecho.

\section{DESARROLLO}

\subsection{IMPORTANCIA DE LA EFECTIVIDAD DEL DERECHO EN LA JURISDICCIÓN DE LO CONTENCIOSO ADMINISTRATIVO}

Los postulados constitucionales que abordan hoy al derecho, como los valores y principios que nuestra carta de derechos fundamental expresa en el entendido del Estado social de derecho, debiendo armonizarse con los retos de una justicia en la posmodernidad a pleno siglo XXI donde el fenómeno de la globalización también operar en el mundo jurídico. Por eso es vital que en la jurisdicción de lo contencioso administrativo este sustento constitucional sirva para dirimir la principal necesidad que esta jurisdicción enfrenta y es precisamente el sentido de justicia, se constituyen así pilares básicos en la consolidación de los principios fundamentes como el de legalidad en todas las actuaciones judiciales, y en el mismo sentido de lo que el derecho administrativo general enmarca para los casos contenciosos, en relación con el crecimiento de las necesidades de la administración. A medida que la intervención y los servicios del Estado se han multiplicado, la administración se ha hecho más compleja y necesita mayor técnica de acción. Al lado de una administración tradicional, de ministerios, gobernaciones, alcaldías, por ejemplo han surgido formas más modernas de gestión en los establecimientos públicos, y en las denominadas empresas públicas, o entidades descentralizadas por servicios. (Vidal, 1994, p.2) 
En esta misma medida se estructuran los parámetros que legitiman el accionar del Estado frente a sus mismas actuaciones, y de las relaciones entre los particulares con el Estado, como las controversias y litigios que emanan de la administración, resaltamos que los postulados centrales que evidencia la inclusión necesaria entre los principios que emanan de la constitución y la aplicación material de las leyes ordinarias y generales del ordenamiento jurídico.

Es así que en una visión del Estado social de derecho, la justicia contencioso administraba debe proveer mecanismos, que garanticen el cumplimientos de sus postulados y principios rectores a la luz de la evolución del Estado de derecho, como esta de protección de los mecanismo legales y disposiciones jurídicas, en el carácter de una justicia que debe adecuarse a los avances del Estado de derecho, ahora social, en la garantía y protección de los derechos fundamentales.

Esto se construye adoptando criterios renovadores de la propia justicia, y del sentido de incluir el principio de los justo, en dicha jurisdicción. El principio de justicia reúne las condiciones de eficacia de los derechos, al llevar esto al plano de la jurisdicción contenciosa, vemos rezagos que no dejan que este principio opere con la mayor optimización de herramientas y recursos destinados a su buen funcionamiento.

Es necesaria adoptar una nueva visión que aborde el problema de la efectividad del derecho en la jurisdicción de lo contencioso administrativo, como la presentación de su objeto de estudio, y la asimilación de sus principales falencias en el modelo judicial para acceder a ella. Como su objeto de estudio determina que las relaciones que suscitan los particulares con el Estado, originan y pueden presentar controversias, y estas a su vez convertirse en hechos litigiosos, la búsqueda debe ser por la protección y el fácil acceso a la jurisdicción.

\subsubsection{Los derechos fundamentales y la acción de tutela}

En este orden de ideas, los derechos fundamentales como derechos tutelables, permiten que a través de ciertos mecanismos protectores se le den aplicación directa e inmediata cuando estos estén en peligro o se vean vulnerados. A la ya reiterada pregunta, ¿todos los derechos fundamentales son tutelables?, podemos responder, que serán tutelables en la medida que estos se acojan a ciertos criterios elaborados por la jurisprudencia de la corte constitucional. Porque la puesta de fundamentación en la acción de tutela está totalmente abierta, es decir los criterios que acoge la corte constitucional pueden variar a lo largo de su desarrollo jurisprudencial, y catalogar derechos fundamentales que antes no eran vistos así, por esta alta corporación. Y no se prevé como una posición cerrada o estricta, en sentido de no permitir la interpretación de estos derechos, así, Chinchilla establece:

Uno de los aportes más significativos y originales de la corte constitucional ha sido la elaboración de una sugestiva teoría según la cual los derechos fundamentales- derechos acorazados con la acción de tutela - son identificables con fundamento en la aplicación de cinco criterios en forma conjunta o complementaria. (Chinchilla, 2009, p. 144)

La Corte en su jurisprudencia, en la Sentencia T-227 de 2003 M.P: Eduardo Montealegre Lynett, ha 
tomado la postura de los cinco criterios y a su vez desarrollando una nueva visión acogiendo a dos criterios, como tesis inicial y la nueva postura que ha elaborado, en un principio se pensó, que solo los derechos catalogados como fundamentales, en la sistemática constitucional, serían el objeto de la acción de tutela como son los derechos del Capítulo 1 del Título 2 de la Constitución, tesis cerrada que no permitía la interpretación con la noción de que el caso concreto, en relación con el estudio del derecho sería el que arrojaría el resultado de fundamentalidad para su posterior protección por vía judicial en la tutela efectiva del mismo, esta postura arrojó una más limitada en la determinación del carácter de fundamentalidad de un derecho para que sea tutelado como lo menciona Chinchilla:

Otra versión aún más limitativa , aunque mejor argumentada, según la cual, los derechos fundamentales tutelables son únicamente aquellos a los que la carta adjudica el carácter de derechos de aplicación directa, es decir los derechos enumerados en la lista taxativa del Art. 85. (2009, p. 145)

Según esta concepción su aplicación atiende a criterios técnicos de viabilidad de un derecho, ya que si corresponde a un criterio, que un derecho fundamental sea tutelado por vía judicial, atendiendo a su aplicación directa, como necesidad de identificar los derechos fundamentales tutelables con soporte en la aplicabilidad directa a partir del solo texto constitucional, otros conceptos no pueden dividirse de los postulados de alternancia constitucional de fundamentalidad de los derechos que son examinados para su protección por vía de tutela. Corresponde lo anterior, a los postulados de alternativa fáctica y medio fáctico, los cuales operan cuando son el único medio para que el derecho fundamental no sea amenazado o vulnerado, como cuando un pensionado reclama el pago total de sus prestaciones sociales a un posible reajuste en su pensión, la aplicación de la acción de tutela resulta como la única alternativa fáctica posible para que su derecho a la seguridad social no sea vulnerado.

\subsection{LA JUSTICIA CONTENCIOSA ADMINISTRATIVA DEBE ARMONIZARSE CON LA NUEVA CARTA DE 1991}

A partir 1991 nace en Colombia una nueva Constitución Política, una carta fundamental de derechos abierta y pluralista, consolidada bajo un gran acuerdo nacional como lo fue la Asamblea Nacional Constituyente que la antecedió, sobre ella se estructuraron los valores, principios y directrices políticas que iban a determinar las relaciones y la convivencia de los nacionales colombianos con todas las autoridades y organismos públicos. Esta noción integró la idea de el por qué el Estado de derecho quedaba atrás y nacía uno nuevo, llamado en Colombia social de derecho pero en otras latitudes, como Europa denominado este como constitucional de derecho, se implementó así una serie de declaraciones especiales a los ciudadanos. Estructurando sobre unos cimientos de libertades, siendo estas individuales y colectivas.

Con relación a esto el derecho administrativo y su justicia contenciosa adquirieron nuevos compromisos de cara a la nueva carta política del 91, estos retos son: acabar con la existencia de barreras tales, como la desigual distribución geográfica de los despachos judiciales, la complejidad o desactualización de la legislación procesal, y los altos costos implícitos en la operación del 
sistema. En el entendido de encontrar equilibrio entre las normas constitucionales y su propia dogmática, mírese el nuevo Código Contencioso, en virtud de eso hay tratadistas que afirman que ya era hora que la justicia contenciosa se armonizara con los principios de la constitución nacional, es así como lo plantea Correa:

En primer término, se propone una adaptación del Código Contencioso Administrativo a las nuevas previsiones adoptadas por la constitución de 1991, en el sentido de que el objeto de la jurisdicción de lo contencioso administrativo no solo comprende el control de legalidad de las actuaciones administrativas, sino también la protección efectiva de los derechos de los administrados. En este mismo sendero, se consagra de manera expresa que los procedimientos ante la jurisdicción de lo contencioso administrativo se deben adelantar conforme a los principios del orden jurídico y buscando la efectividad de los derechos reconocidos en la constitución política y la ley, de suerte que en la aplicación e interpretación de las normas deberá observarse los principios constitucionales y los generales del derecho procesal. (Correa, 2010, p. 511)

\subsection{EL FUNCIONAMIENTO Y ACCESO A LA ADMINISTRACIÓN DE JUSTICIA, UNA REALIDAD QUE NOS INTERESA A TODOS}

El derecho de acceso a la administración de justicia a rasgos generales, se instituye como un verdadero servicio público, el cual deben gozar satisfactoriamente todos los ciudadanos colombianos. Bajo esta premisa es claro que la visión de este derecho como reconocimiento del Estado social de derecho, garantiza el cumplimiento de sus postulados fundamentales, referentes al buen funcionamiento de la rama judicial del poder público. El descontento que presenta la prestación de este servicio esencial, estipulado bajo la concepción integradora de justicia y sociedad, aquella que pregona el esclarecimiento de las controversias humanas, a través de los medios idóneos para ello, en este caso hablamos de los tribunales, despachos judiciales, y demás organismos investidos con jurisdicción funcional y competencia facultativa, para conocer de los procesos que se convierten a veces en verdaderas batallas campales, si esto es así, no sería necesario fortalecer aún más nuestro aparato judicial, para el amparo y la protección tutelar de los derechos cumplan una labor garantista dentro del Estado social de derecho, la respuesta a esto, claramente debe ser afirmativa, buscando misión renovadora en el ejercicio adecuado de los derechos.

Los retos que reclama la justicia, en este nuevo milenio son avallazadores, y buscan primordialmente impregnar a la justicia, con un sentido claro de credibilidad y confianza, que la gente del común, se sienta tranquila cuando acude a los despachos judiciales a que sus controversias sean resueltas en derecho, y con criterios jurídicos acertados y adecuados a cada caso en particular. En una visión de la justicia como derecho fundamental, se consagra la virtualidad de su acceso, y esto se traduce materialmente, de si las personas comunes y corrientes pueden acceder al aparato jurisdiccional del Estado a que sus controversias lleguen a felices términos, cuando hablamos de feliz término, nos referimos que dentro de los procesos juridiciales sean observados y respetados, los derechos fundamentales, como el debido proceso, el derecho de defensa, el de las dos instancias, la prevalencia del derecho sustancial sobre las formalidades legales, el juez natural, entre otros, todos estos derechos fundamentales del proceso, cumplen una 
función social dentro del entendido del Estado de derecho, y es principalmente equilibrar las cargas, y no balancear los derechos por pasiones o criterios subjetivos de los funcionarios o adiestradores de justicia, es claro que el derecho de hoy reclama, seriedad y prontitud en sus decisiones judiciales.

La crisis es clara, vemos que las cosas en la justicia no andan muy bien, y a todos nos debería interesar esta realidad, como fundamento de esto observamos la deslegitimidad que está sufriendo nuestro derecho judicial, y a esto debe sumárseles los problemas operacionales y de funcionamiento que se ven en la mora judicial y congestión de los estrados judiciales. Pérez reflexiona al respecto:

El derecho de acceso a la administración de justicia en sentido abstracto es perfecto, como tal está contemplado en la Constitución Política. El problema es su materialización, diría que es la constante de todos los derechos humanos cualesquiera que sean, unos más, unos menos, pero ninguno opera de manera perfecta. El no tener recursos económicos suficientes para acudir al aparato judicial, el no contar con las herramientas tecnológicas para resolver determinados asuntos objeto de conocimiento de los jueces, la insuficiencia de recurso humano idóneo para resolver de manera adecuada y pronta las controversias judiciales puestas a su conocimiento, la no existencia de procesos ágiles para resolver causas donde se controviertan derechos distintos de los fundamentales, así como la ineficacia en la ejecución de muchas sentencias, son, entre otras, algunas de las causas para decir que en nuestro país no existe un verdadero derecho de acceso a la administración de justicia. (Pérez, 2010, p. 583-584)

\subsection{EL ALCANCE DEL DERECHO FUNDAMENTAL DE ACCESO A LA ADMINISTRACIÓN DE JUSTICIA, SU SENTIDO JURISPRUDENCIAL}

La jurisprudencia de la corte constitucional ha sido clara al respecto del alcance del derecho fundamental de acceso a la administración de justicia, y lo consolida como un verdadero pilar de los postulados constitucionales del Estado social de derecho. Analicemos puntualmente lo que ha dicho la corte en su jurisprudencia:

El Artículo 229 de la Constitución Política consagra expresamente el derecho de acceso a la administración de justicia, también llamado derecho a la tutela judicial efectiva, el cual se traduce en la posibilidad reconocida a todas las personas residentes en Colombia de poder acudir en condiciones de igualdad ante los jueces y tribunales de justicia, para propugnar por la integridad del orden jurídico y por la debida protección o el restablecimiento de sus derechos e intereses legítimos, con estricta sujeción a los procedimientos previamente establecidos y con plena observancia de las garantías sustanciales y procedimentales previstas en la ley. (Corte Constitucional, Sentencia C- 426 de 2002. M.P: Rodrigo Escobar Gil)

Este derecho se funda en el entendido del Estado constitucional contemporáneo, el cual presenta tres características principales, las garantías o mecanismos de protección constitucional de los derechos fundamentales, la fuerza normativa de la constitución, y la prevalencia de la constitución sobre la ley como sentido de todo el ordenamiento jurídico. En el caso concreto el alcance del 
derecho fundamental de acceso a la administración de justicia, consagrado en la norma superior en su Artículo 229, nos muestra como debe ser entendido este para encontrar su predominio en la justicia material, y como se había mencionado, siempre mirando los postulados centrales del Estado social de derecho. Hablamos de la tutela judicial efectiva, cuya facultad principal es armonizar los derechos subjetivos de los ciudadanos, en el marco sustancial, al llevarlos a un plano material y concreto, que estos lleven inmersos técnicas de garantía, y mecanismos de protección reales y efectivos, para contrarrestar sus posibles vulneraciones.

Continuando con este entendido, la relación directa entre el derecho fundamental de acceso a la administración de justicia, y la tutela judicial efectiva, que sobre este derecho se ejerce, debe responder a criterios tales, como la orientación estatal, de la misma función pública administrativa, ya que existiendo una relación directa con las garantías inalienables de los asociados, su deber es el de velar por los interese superiores de una sociedad, y del amparo de los derechos de la colectividad o colectivos. Como sustento del marco constitucional tenemos:

\begin{abstract}
El derecho constitucional de acceso a la administración de justicia, ha sido calificado por la corte como un derecho medular, es decir como la garantía real y efectiva que el Estado le ofrece al individuo, de poder acudir, para resolver las controversias que surjan con otros individuos u organizaciones y con el mismo Estado, ante un juez, con miras a obtener una resolución motivada, ajustada a derecho, y dictada de conformidad con el procedimiento y las garantías constitucionales previstas en la constitución y en la ley. (Corte Constitucional, Sentencia T-476 de 1998. M.P: Fabio Morón Díaz)
\end{abstract}

Esta noción del entendido real de la tutela judicial efectiva, sobre los derechos de acceso a la administración de justicia, distingue el amparo especial que se deben ejercer sobre los derechos fundamentales tutelares en el marco de la sociedad y el Estado, la visión que nosotros respaldamos aquí, es que no solo el reconocimiento de los derechos humanos, como límites materiales a la actividad del gobierno y los particulares, encuentra su característica en un Estado democrático contemporáneo, sino además el mismo principio de justicia en el derecho, debe buscar la misma misión, con la que pretende reivindicar el Estado social la tutela judicial efectiva, y esto se conseguirá solo, con una reestructuración de la misma rama judicial del poder público.

\title{
2.5 ¿ESTÁ AL ALCANCE DE TODOS LOS COLOMBIANOS ACCEDER A LA JURISDICCIÓN CONTENCIOSA ADMINISTRATIVA?
}

Cuál es el alcance real de la jurisdicción contenciosa administrativa en Colombia. Esta jurisdicción se comprende en una justicia excluyente de los casos menores y de mínima cuantía, los gastos de trámite y de operatividad para que los procesos tomen su curso natural, son exageradamente elevados, al costo que se convierte en una limitante material para el goce efectivo del derecho fundamental de todo ciudadano de acceder a la jurisdicción contencioso administrativa, cuando considere que la administración le ha vulnerado o menoscabado algún interés suyo o se haya ocasionado una detrimento o reducción de su patrimonio, o es más la puesta en peligro de un bien jurídico tutelado por el ordenamiento jurídico colombiano.

Así las cosas, la justicia administrativa, y la jurisdicción contencioso administrativa, se convierte en 
una justicia de elite, donde para acudir a ella necesariamente se tendría que contar, con el acompañamiento del ejercicio profesional de un abogado, porque nos pensar en que la mayoría de la población, que acude esta justicia busca la reparación integral, de una derecho que se ha lesionado, pensándose a veces en prestaciones económicas sustanciales, con las cuales las condiciones monetarias resultan insuficientes.

El objeto central de este artículo, se consolida sobre la base de la discusión, si materialmente la ciudadanía en general disfruta del derecho de acceso a la administración de justicia, en la jurisdicción contencioso administrativa, como derecho fundamental efectivo, observemos al respecto la posición de Pérez:

No se conocen datos que demuestren cifras o porcentajes concretos sobre este aspecto, pues generalmente todas las estadísticas son sobre información derivada de los procesos judiciales, es decir, sobre quien ya tuvo la oportunidad de acceder al servicio judicial, pero lo que interesa para resolver la pregunta son las que no lo han hecho o no han acudido a ella y, definitivamente, no hay respuesta por ahora. (2010, p. 584)

El panorama es desolador, ya que si miramos el objeto de la jurisdicción contencioso administrativa, el cual es la de solucionar los litigios, y controversias que emanen entre los particulares y el aparato estatal, en relación de actos y negocios jurídicos que ambos hayan realizados, es grave desde el punto de vista del principio de justicia, esta situación que genera la no posibilidad de acceder al contencioso, para que un juez, tribunal, o en último un cuerpo colegiado superior, resuelva la controversia.

Continuando con la línea del mismo autor aquí citado, encontramos la siguiente concepción, que demuestra el limitante material de la jurisdicción contencioso administrativa:

Se podría plantear como hipótesis que son miles los colombianos que no acceden a la jurisdicción contenciosa administrativa porque es una justicia limitativa, es decir, que las personas de condiciones económicas bajas no tienen la misma posibilidad de acceso a la justicia que aquellos que cuentan con una mejor condición económica. Para resolverla tenemos que decir que a pesar de ser gratuito el acceso a la administración de justicia, no lo son los gastos que hay que asumir en la presentación y trámite del proceso, así como el pago de los honorarios profesionales de los abogados que los representen. Sobre todo este último aspecto es el más complejo para quienes no encuentran con recursos económicos suficientes y sus causas no resultan atractivas para ser atendidas a resultado. (Pérez, 2010, p. 584)

\subsection{CRITERIOS DE SOLUCIÓN A LA PROBLEMÁTICA DEL ACCESO A LA JURISDICCIÓN CONTENCIOSA ADMINISTRATIVA}

Mirar el acceso a la justicia contencioso administrativa como verdadero derecho fundamental, es concordar de manera efectiva las normas internacionales de protección a los derechos humanos integradas al ordenamiento colombiano, a través de la constitución en el bloque de constitucionalidad, que en rasgos de operatividad del derecho se traduce en la aplicación eficaz del derecho. La efectividad de los derechos se traduce en la necesidad de cambio en el paradigma de la 
justicia tradicional, aquella que se encargaba de la insuficiencia de los problemas sociales traducidos en litigios jurídicos, y no daba respuestas a cambios estructurales.

Hoy el derecho debe ser preventivo, conciliador y armonizador de todas las relaciones sociales, esta noción se enmarca con mayor injerencia en los derechos fundamentales, aquellos derechos que van de la mano con el hombre por que traduce su propia actividad con la comunidad y el entorno en que se desarrolla. El ordenamiento jurídico colombiano establece herramientas y mecanismos de protección de los derechos fundamentales como valores superiores del Estado social de derecho, orientado a todas sus instituciones, es así que enfrenta nuevos retos en la aproximación conceptual necesaria entre derecho común, y derecho supra-jerárquico.

Lo que significa que no solo será derecho aquella disposición que así lo parezca en su contenido sino en su interacción con el problema social o con la consecuencia material que así lo origina. La relación con el acceso a la justicia contenciosa administrativa se traduce en la solución al mal funcionamiento de nuestra administración de justicia de manera inoperante y precaria.

Es vital que en la justicia contenciosa administrativa este paradigma de renovación se solidifique en el entendido de su propia misión como verdadero derecho fundamental efectivo a su operatividad y respuesta a una justicia acertada. El problema se evidencia en cómo es mirada hoy esta jurisdicción de la justicia ordinaria, sus instituciones y fenómenos jurídicos, de cómo se enfrentan sus necesidades principales, y si evidencia su sustento en el fundamento constitucional, de posibilidades reales como derecho fundamental efectivo y eficaz. Que vaya acorde con los principios de celeridad, oportunidad, y aplicación efectiva de las normas en el caso concreto, distinguiendo así cuales son los principios fundamentales en la consecución de los mismos fines.

En síntesis, El derecho de acceso a la administración de justicia a rasgos generales, se instituye como un verdadero derecho fundamental, el cual deben gozar satisfactoriamente todos los ciudadanos colombianos. Bajo esta premisa es claro que la visión de este derecho como reconocimiento del Estado social de derecho, garantiza el cumplimiento de sus postulados fundamentales, referentes al buen funcionamiento de la rama judicial del poder público.

Se presenta un descontento, en la prestación de este derecho esencial, estipulado bajo la concepción integradora de justicia y sociedad, aquella que pregona el esclarecimiento de las controversias humanas, a través de los medios idóneos para ello, en este caso hablamos de los tribunales, despachos judiciales, y demás organismos investidos con jurisdicción funcional y competencia facultativa, para conocer de los procesos que se convierten a veces en verdaderas batallas campales, si esto es así, no sería necesario fortalecer aún más nuestro aparato judicial, para el amparo y la protección tutelar de los derechos cumplan una labora garantista dentro del Estado social de derecho, la respuesta a esto, claramente debe ser afirmativa, buscando misión renovadora en el ejercicio adecuado de los derechos. 


\section{CONCLUSIONES}

La realidad que refleja la jurisdicción contenciosa administrativa, es que en el estado colombiano todavía existen desigualdades en el campo del acceso a la administración de justicia, entendida esta como un derecho fundamental que por mandato expreso de la Constitución Art. 229 deben gozar todos los ciudadanos. Vemos que la justicia contenciosa en una justicia de alto costo por lo que refleje la puesta en marcha de dicho sistema juridicial, y que solo es posible acceder a el a través de un abogado capacitado para representar judicialmente a aquellas personas que así lo necesitan. Finalmente si el derecho administrativo y su justicia, se instituyeron como una jurisdicción por medio de la cual se resolverían las controversias que suscitaran de las relaciones del estado con los particulares, esta justicia y su sistema judicial debe ser ejemplo de operatividad y de cumplimiento de los postulados de una justicia con prontitud, agilidad, fácil acceso, celeridad y eficacia.

\section{REFERENCIASBIBLIOGRÁFICAS}

CARRILLO, Y. (2008) "Temas y problemas de la filosofía del derecho". Ediciones doctrina y ley, primera edición, Bogotá, Colombia.

CHINCHILLA, T. (2009) “¿Qué son y cuáles son los derechos fundamentales? Las nuevas líneas de la jurisprudencia". Segunda edición, editorial Temis, Bogotá, Colombia.

CORREA, R. (2010) "Jurisdicción contencioso administrativa y derecho fundamental de acceso a la justicia". Memorias del XXXI congreso colombiano de derecho procesal, Universidad Libre, Bogotá, Colombia.

OSPINA, A. (2009) “De la jurisdicción administrativa a la jurisdicción de lo contencioso administrativo: ¿un viaje de ida y vuelta?", Universidad Externado de Colombia. Bogotá, Colombia.

PÉREZ, D. (2010) “El derecho de acceso a la administración de justicia en la jurisdicción contenciosa administrativa". Memorias del XXXI congreso colombiano de derecho procesal, Universidad Libre, Bogotá, Colombia.

VIDAL, J. (1994) “Derecho administrativo”. Décima edición, editorial Temis, Bogotá, Colombia. 